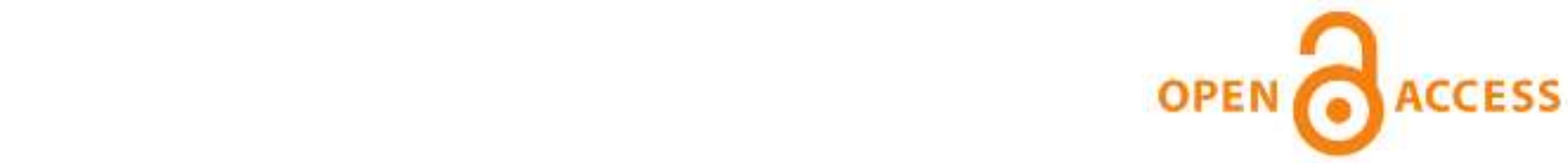 \\ International Journal of Social Sciences and Management \\ A Rapid Publishing Journal
}

ISSN 2091-2986

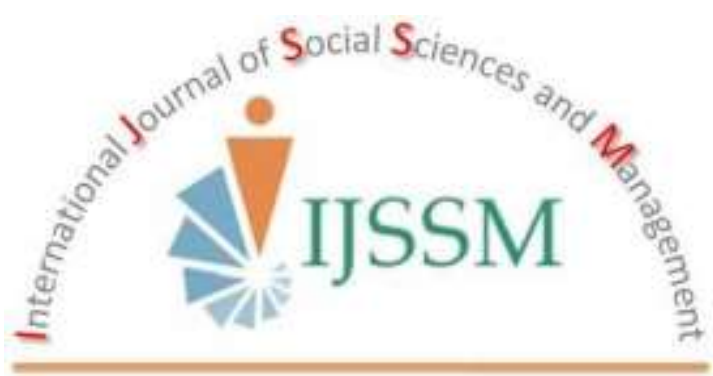

\section{Indexing and Abstracting}

CrossRef, Google Scholar, International Society of Universal Research in Sciences (EyeSource), Journal TOCs, New Jour, Scientific Indexing Services, InfoBase Index, Open Academic Journals Index (OAJI), Scholarsteer, Jour Informatics, Directory of Research Journals Indexing (DRJI), International Society for Research Activity (ISRA): Journal Impact Factor (JIF), Simon Fraser University Library, etc.

Vol- 3(1), January 2016 


\title{
Research Article \\ CONSTRUCTION AND STANDARDIZATION OF SCIENTIFIC APTITUDE TEST (SAT) FOR SECONDARY SCHOOL STUDENTS-A PILOT STUDY
}

\author{
P PandiaVadivu ${ }^{1}$, R Sridhar ${ }^{*}$ and B Mohan Kumar ${ }^{2}$ \\ ${ }^{1}$ School of Education (Cognitive Science), Tamilnadu Open University, Saidapet, Chennai-600 015, Tamilnadu, India \\ ${ }^{2}$ School of Education, Pondicherry Central University, Puducherry-605 014, India \\ *Corresponding Author’s Email: edusri.tn@gmail.com
}

\begin{abstract}
The main objective of the present pilot study was to construct and standardize a Scientific Aptitude Test (SAT) for the secondary school science students (Grade 9 and 10). The test items (30 questions) were prepared by the researchers based on the five important aspects in scientific thinking such as Analogy, Scientific reasoning, Numerical ability, Logical reasoning and Comprehension based questions. A test of multiple choice items were used as a data collection instrument in the six different schools in the selected districts in Tamilnadu, India. The computer based Microsoft excel spreadsheet (2007) was prepared to document the obtained score and the same used for statistical analysis. Through recent method of item analysis, Cronbach's Alpha values were computed using IBM SPSS software. The reliability coefficients were found 0.874(Spearman-Brown) and 0.672(Guttmann Split-Half). Hence, the present pilot study revealed that the scientific aptitude test for secondary students to ignite their scientific temper and also useful in preparing future competitive examinations.
\end{abstract}

Key words: Aptitude; Cronbach's alpha; IBM SPSS software; Reliability; Secondary; Science.

\section{Introduction}

Science is a systematic enterprise that builds and organizes knowledge in the form of testable explanations and predictions about the universe (Edward, 1999). According to Business Dictionary, Aptitude is defined as natural ability for learning and proficiency in a specific area or discipline. Aptitude is expressed in interest and reflected in current performance which is expected to improve over time with training. Scientific aptitude is used to measure innate capacity of an individual. It also reflects the effect of learning with encouraging higher order thinking skills.

\section{Statement of problem}

The researchers have formulated the problem for the present pilot study as "Construction and standardization of scientific aptitude test of secondary school students".

\section{Literature Review}

There are several studies had conducted in scientific attitude (Grewal, 1977; Baker, 1985; Patricia, 1985; Elizabeth et al. 2011) among school students, but less number of studies are conducted (Patel, 2010) in scientific aptitude for school students. Hashmi et al. (2012) had developed and validated an aptitude test for secondary school mathematics students. A total of 454 students were participated from two districts (Bahawalpur and Multan) in Pakistan. The researchers were standardized 50 items after pilot study. The reliability coefficient was found 0.82 . The another study conducted by Yeli and Sadiqa (2013) had studied the learning achievement in science of secondary school students in relation to their scientific aptitude. The study was conducted among 800 students belonging to class $9^{\text {th }}$ of Karnataka state, India. The investigators concluded that the unaided secondary school students have higher scientific aptitude scores than aided and government school students.

\section{Need for the Study}

The review of related literature showed that there are very less number of tools are available for secondary school student for testing their scientific aptitude. Hence the present study was undertaken to conduct pilot study on construction and standardization of an aptitude test in science for secondary school students of selected districts of Tamilnadu state in India.

\section{Objectives}

I. To construct and standardize Scientific Aptitude Test(SAT) for secondary school students

II. To find out secondary school science students' aptitude test score

III. To analyze the test items using Cronbach's Alpha values

IV. To establish reliability of Scientific Aptitude Test(SAT) for secondary school students

\section{Delimitation}

i. The study was confined to 6 schools only 
ii. The board of studies such as International Baccalaureate(ID), International CBSE (ICBSE) and Indian Certificate of Secondary Education (ICSE) are not included in the study because

a) In the state of Tamilnadu, the first main board of study is Equitable/uniform pattern of education and then followed by Central Board of Secondary Education (CBSE).

b) Since less population in the other boards, the present study is not involved the above mentioned board of studies.

\section{Method}

The present study was carried out using survey as the research method. The pilot study on the Science Aptitude test for secondary school students was developed after an exploration of related literatures. The test items were prepared by the researchers from the state and central textbooks of Science of secondary school.

\section{Population and sample}

The students studying in grade 9 and 10 were randomly selected for the pilot study. There were belonging to two districts (Chennai and Thiruvallur) of Tamilnadu, India. A total of 6 different schools were involved in the pilot study.

\section{Development of the Test}

The test items were developed by the investigators based on the five subscales i.e., Analogy, Scientific reasoning, Numerical ability, Logical reasoning and Comprehension based questions. There were four options in each subscale in the form of multiple choice questions except in analogy (pick the odd one out). Initially there were 30 items in five different dimensions of the developed tool. The content was validated by the five experts in the field of science education.

\section{Pilot study and Finalization of the Tool}

The test items were administrated to 93 secondary school students belonging to six different schools Chennai and Thiruvallur districts, Tamilnadu, India. The collected data were evaluated by awarding one mark for each correct response and zero for each incorrect response. Then the scores obtained by the respondents $(\mathrm{N}=93)$ were documented in Microsoft excel spreadsheet (2007) for statistical analysis using IBM SPSS software (version 19.0). In this present pilot study the test items were analyzed using Cronbach's Alpha values (Cronbach, 1951). The values above 0.7 are often considered to be acceptable, if the value is below that said level then the item should be remodified and a pilot study has to be conducted or else the item can be omitted.

\section{Statistical Techniques Used}

Mean (M), Standard Deviation (SD), variance, Cronbach's Alpha values, percentage analysis, reliability values by Spearman-Brown and Guttmann Split-Half coefficients were employed for analysis of the data.

\section{Analysis and Interpretation of Data}

The results are analyzed using item statistics (mean, standard deviation and variance), reliability values and item analysis. The Characteristics of the variables with respect to the respondents are shown in the Table 1.

Table 1: Characteristics of the variables with respect to the respondents

\begin{tabular}{|c|c|c|c|c|c|}
\hline S.No. & Variables & Categories & Frequency & Percentage & Total \\
\hline \multicolumn{6}{|c|}{ Students Profile } \\
\hline \multirow[t]{2}{*}{1.} & Gender & Male & 48 & 51.6 & 93 \\
\hline & & Female & 45 & 48.4 & \\
\hline \multirow[t]{2}{*}{2.} & studying class & IX & 27 & 29 & 93 \\
\hline & & $\mathrm{X}$ & 66 & 71 & \\
\hline \multicolumn{6}{|c|}{ Institutional profile } \\
\hline \multirow[t]{2}{*}{1} & Board of affiliation & State & 76 & 81.7 & 93 \\
\hline & & Central(CBSE) & 17 & 18.3 & \\
\hline \multirow[t]{3}{*}{2.} & Type of management & Government & 10 & 10.8 & 93 \\
\hline & & Government Aided & 10 & 10.8 & \\
\hline & & Private & 73 & 78.4 & \\
\hline \multirow[t]{2}{*}{3.} & Locality & Urban & 20 & 21.5 & 93 \\
\hline & & Rural & 73 & 78.5 & \\
\hline \multirow[t]{2}{*}{4.} & Medium of instruction & Tamil & 15 & 16.1 & 93 \\
\hline & & English & 78 & 83.9 & \\
\hline
\end{tabular}


The scores obtained by the respondents $(\mathrm{N}=93)$ were documented in Microsoft excel spreadsheet (2007) for statistical analysis using IBM SPSS software. The item statistics such as mean and standard deviation, reliability values using Spearman-Brown(0.874) and Guttmann SplitHalf coefficients(0.672) and item analysis of Cronbach's Alpha values were computed. The findings show that the most of the items were falling in the acceptable range of
Cronbach's alpha values (Barua et al. 2013) above 0.7. However, some items were omitted due to their less value. Overall, 25 test items were selected in the standardized scientific aptitude test for secondary school students. The item analysis using Cronbach's Alpha values is shown in Table 2 and an overview of graphical representation of item analysis perceived by the respondents is shown in the Fig. 1 .

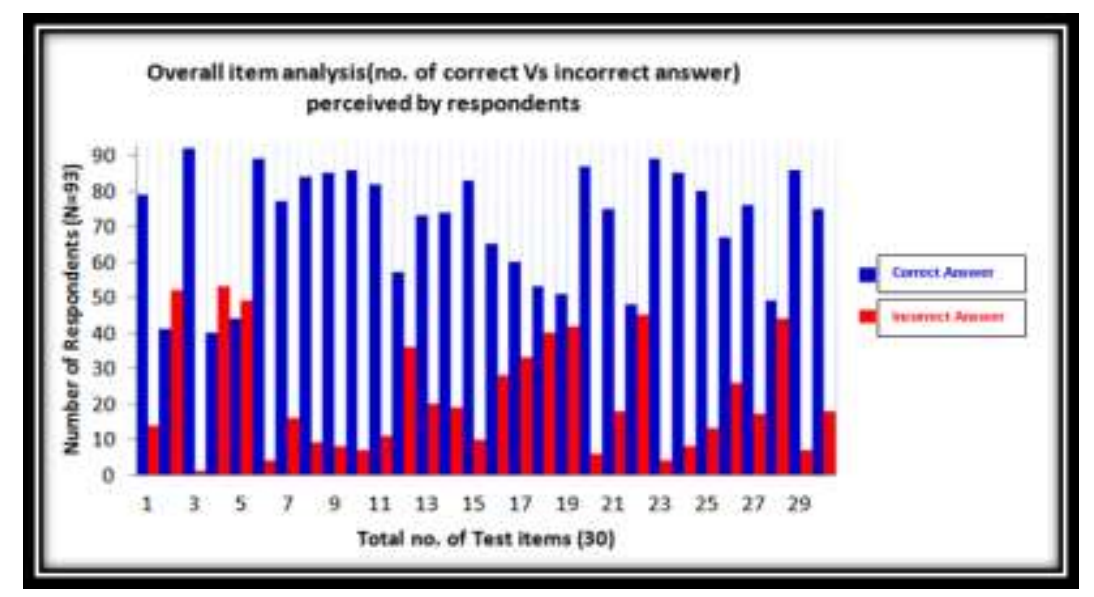

Fig. 1: Overall item analysis (No. of correct Vs incorrect answer) perceived by the secondary school students

Table 2: Item analysis using Cronbach's Alpha values

\begin{tabular}{|c|c|c|c|c|c|c|c|c|}
\hline Item No. & Mean & $\begin{array}{c}\text { Standard } \\
\text { Deviation }\end{array}$ & $\begin{array}{l}\text { Scale Mean } \\
\text { if Item } \\
\text { Deleted }\end{array}$ & $\begin{array}{l}\text { Scale Variance if } \\
\text { Item Deleted }\end{array}$ & $\begin{array}{c}\text { Corrected Item- } \\
\text { Total } \\
\text { Correlation }\end{array}$ & $\begin{array}{c}\text { Cronbach } \\
\text { Alpha if Item } \\
\text { Deleted }\end{array}$ & $\begin{array}{c}\text { Round off } \\
\text { values }\end{array}$ & Item Status \\
\hline ITEM_1 & .90 & .303 & 43.14 & 70.286 & .198 & .703 & 0.7 & Selected \\
\hline ITEM_2 & .46 & .503 & 43.58 & 67.310 & .463 & .691 & 0.7 & Selected \\
\hline ITEM_3 & .88 & .327 & 43.62 & 69.118 & .301 & .700 & 0.7 & Selected \\
\hline ITEM_4 & .42 & .499 & 41.62 & 61.118 & .116 & .614 & 0.6 & Not Selected \\
\hline ITEM_5 & .48 & .505 & 43.56 & 67.190 & .476 & .690 & 0.7 & Selected \\
\hline ITEM_6 & .96 & .198 & 43.08 & 71.014 & .100 & .706 & 0.7 & Selected \\
\hline ITEM_7 & .86 & .351 & 43.18 & 69.906 & .232 & .702 & 0.7 & Selected \\
\hline ITEM_8 & .84 & .370 & 43.20 & 68.735 & .409 & .696 & 0.7 & Selected \\
\hline ITEM_9 & .86 & .351 & 43.18 & 68.436 & .487 & .695 & 0.7 & Selected \\
\hline ITEM_10 & .92 & .274 & 43.12 & 69.169 & .470 & .697 & 0.7 & Selected \\
\hline ITEM_11 & .88 & .328 & 43.16 & 69.607 & .305 & .700 & 0.7 & Selected \\
\hline ITEM_12 & .64 & .485 & 42.40 & 62.061 & .259 & .621 & 0.6 & Not Selected \\
\hline ITEM_13 & .76 & .431 & 43.28 & 70.655 & .075 & .706 & 0.7 & Selected \\
\hline ITEM_14 & .76 & .431 & 43.28 & 67.144 & .574 & .689 & 0.7 & Selected \\
\hline ITEM_15 & .88 & .328 & 43.16 & 70.586 & .126 & .705 & 0.7 & Selected \\
\hline ITEM_16 & .68 & .471 & 43.36 & 66.521 & .604 & .686 & 0.7 & Selected \\
\hline ITEM_17 & .54 & .503 & 43.50 & 65.847 & .647 & .683 & 0.7 & Selected \\
\hline ITEM_18 & .52 & .505 & 41.52 & 60.091 & .365 & .605 & 0.6 & Not Selected \\
\hline ITEM_19 & .54 & .503 & 43.50 & 68.704 & .291 & .698 & 0.7 & Selected \\
\hline ITEM_20 & .98 & .141 & 43.06 & 71.119 & .104 & .706 & 0.7 & Selected \\
\hline ITEM_21 & .72 & .454 & 43.32 & 69.773 & .186 & .702 & 0.7 & Selected \\
\hline ITEM_22 & .54 & .503 & 42.50 & 61.459 & .321 & .619 & 0.6 & Not Selected \\
\hline ITEM_23 & .98 & .141 & 43.06 & 70.302 & .449 & .702 & 0.7 & Selected \\
\hline ITEM_24 & .90 & .303 & 43.14 & 70.939 & .070 & .706 & 0.7 & Selected \\
\hline ITEM_25 & .80 & .404 & 43.24 & 69.166 & .306 & 699 & 0.7 & Selected \\
\hline ITEM_26 & .70 & .463 & 43.34 & 68.025 & .412 & .694 & 0.7 & Selected \\
\hline ITEM_27 & .78 & .418 & 43.26 & 68.237 & .430 & .694 & 0.7 & Selected \\
\hline ITEM_28 & .90 & .303 & 42.14 & 60.307 & .394 & .600 & 0.6 & Not Selected \\
\hline ITEM_29 & .54 & .503 & 43.50 & 68.051 & .371 & .695 & 0.7 & Selected \\
\hline ITEM_30 & .78 & .418 & 43.26 & 69.870 & .192 & .702 & 0.7 & Selected \\
\hline
\end{tabular}




\section{Conclusion}

This study was about the construction and standardization of scientific aptitude test for secondary school students. The Scientific Aptitude Test (SAT) was constructed and standardized by the researchers. Out of 30 constructed test items, 25 items were standardized based on Cronbach's Alpha values. Therefore, the scientific aptitude test can be given for various purposes such as to test the scientific aptitude level of secondary school students, to standardize the sample for conducting experimental studies in education, during higher secondary school admission, to prepare for future competitive examinations etc., It is also useful for science faculties give guidance and counseling to the students who scores less in SAT.

\section{Futurology}

The present pilot study propounded that there are new prospective studies for further research in the chosen topic, namely scientific aptitude test and academic stress of school students could be studied. The effect of other variables on the aptitude of school students is also another interesting study. Furthermore, many items can be included in the different dimensions of aptitude test for higher educational levels.

\section{Acknowledgement}

The authors are thankful to Mrs. Sangeetha Sridhar for helping in the correction and uploading of data in MS-excel spreadsheet.

\section{References}

Baker DR (1985) Predictive value of attitude, cognitive ability, and personality to science achievement in the middle school. .Journal of Research in Science Teaching 22(2): 103-113.

Barua A, Kademane K, Gubbiyappa SK, Verma RK, Iqbal MS and AL-Dubai SAR (2013) A tool for decision-making in Norm-referenced survey questionnaires with items of continuous variables. Journal of Asian Scientific Research. 3(11): 1109-1118.

Cronbach LJ (1951) Coefficient alpha and the internal structure of tests. Psychometrika 16: 294-334.

Edward W (1999) Consilience: the unity of knowledge, New York, Vintage.

Elizabeth AD, Scott AP and Vicky B (2011) Gender differences in science-related attitude and interests among middle and high school students. Fall (Science Educator) 20(2): 2330 .

Grewal A (1977) Science Attitude Scale. Published by National Psychological Corporation, Kacheri Ghat, Agra, India.

Hashmi MA, Zeeshan A, Saleem M and Akbar RA (2012) Development and Validation of an Aptitude Test for Secondary School Mathematics Students. Bulletin of Education and Research 34(1): 65-76.

Patel DR (2010) A study of scientific aptitude of students of secondary schools. Sansodhan e-Journal 8(2): 1-5.

Patricia BE (1985) Attitude research in science education. ERIC Clearing- house of Science, Mathematics and Environmental Education Information Bulletin, No.1, Ohio State University, Columbus, $\mathrm{OH}$.

Yeli RS and Sadiqa AD (2013) Learning achievement in science of secondary school students in relation to their scientific aptitude. Research Evaluation and Analysis 45: 51-52. 


\section{Appendix-I}

Short description of SAT in the final draft

\begin{tabular}{|c|c|}
\hline Item No. & SUBSCALES AND SHORT DESCRIPTION OF QUESTIONS \\
\hline \multicolumn{2}{|r|}{ ANALOGY TYPE OF QUESTIONS } \\
\hline 1 & Stars, Moon, Clouds, Planets \\
\hline 2 & Stem, Root, Leaf, Petiole(leaf Stalk) \\
\hline 3 & Potassium, Sodium, Platinum, Calcium \\
\hline 4 & Xylem tracheid, Xylem parenchyma, Xylem vessel, Xylem fibre \\
\hline 5 & Solute, Metal, Solvent, Solution \\
\hline \multicolumn{2}{|r|}{$\begin{array}{l}\text { SCIENTIFIC REASONING } \\
\end{array}$} \\
\hline 1 & Assertion and reason type question based on photosynthesis \\
\hline 2 & Pigment colors in chlorophyll and hemoglobin \\
\hline 3 & Chemical reaction in the formation of zinc sulphate \\
\hline 4 & SI unit of force \\
\hline 5 & Electric circuit diagram identification \\
\hline \multicolumn{2}{|r|}{ NUMERICAL ABILITY } \\
\hline 1 & The total number of chromosomes present in the diploid cell of the human body \\
\hline 2 & Calculation based on second law of reflection \\
\hline 3 & The symbols of sodium and chloride ions \\
\hline 4 & Calculation based on electric energy in $\mathrm{kWh}$ \\
\hline 5 & $10 \%$ law in flow of energy in an ecosystem \\
\hline \multicolumn{2}{|r|}{ LOGICAL REASONING } \\
\hline 1 & The best relation diagram between Parents, Mother and Father \\
\hline 2 & Identify the mismatched pair \\
\hline 3 & Number and alphabet coding and decoding \\
\hline 4 & Rearrange the scrambled words \\
\hline 5 & Identify the word which is different from the rest \\
\hline \multicolumn{2}{|r|}{ COMPREHENSION BASED QUESTIONS } \\
\hline 1 & Identify the scientist who referred the law of octaves \\
\hline 2 & How many total elements were classified according to above mentioned classification of elements? \\
\hline 3 & Find out the number of elements in each group \\
\hline 4 & Air, Water, Soil, Light and Temperature in the environment are called \\
\hline 5 & $\ldots$ are the producer and ___ and ___ are the decomposer. \\
\hline
\end{tabular}

